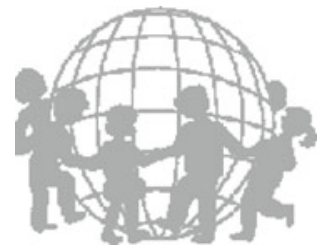

\title{
Invitation: Special Issue Children's Perspectives in Research and Early Childhood Education
}

\author{
(C) Springer Science+Business Media B.V. 2011
}

The International Journal of Early Childhood has a specific history and a specific goal; to work for children's right to education and care all over the world. The UN Convention on the Rights of the Child is the base of the extensive work of OMEP. This is the focal point and the uniqueness of this journal through its association with OMEP and its mission. With this special issue we are proud to invite researchers from different disciplines and with different theoretical perspectives to contribute to a scientific discussion around how children's perspectives are incorporated into early childhood research. The aim of this special issue of IJEC is to critically analyse the possibilities and limitations for doing research with children, involving children's perspectives, and to look at these discourses from a critical perspective. The concept of 'children's perspectives' is defined in a broad way for this special issue. Researchers may focus on interconnected concepts, for example, participation, social justice, and children's rights. We welcome a variety of contributions from empirical to theoretical analyses from different disciplines and theoretical positions.

Please send an abstract of 400-500 words not later than October 10th, 2011 to the editors responsible for this special issue; Eva Johansson eva.johansson@uis.no and Donna Berthelsen d.berthelsen@qut.edu.au. 